\title{
Effect of neoadjuvant chemotherapy and its correlation with HPV status, EGFR, Her-2-neu, and GADD45 expression in oral squamous cell carcinoma
}

\author{
Manoj Pandey ${ }^{1 *}$ (D) Krishna Kiran Kannepali ${ }^{1}$, Ruhi Dixit ${ }^{2}$ and Mohan Kumar $^{3}$
}

\begin{abstract}
Background: Head and neck cancers are the commonest cancer in Southeast Asia. Despite being a surface cancer, it is associated with significant morbidity as despite early detection by the patients they often report for treatment late and hence are associated with poor prognosis. The role of neoadjuvant chemotherapy in head and neck cancer is still under evaluation; there is a large subgroup of population that does not respond to chemotherapy, and hence, most studies have failed to show any survival benefit. This study evaluated the role of neoadjuvant therapy with docetaxel and carboplatin in patients with oral cancer and correlated the response to human papilloma virus, EGFR1, EGFR2, and GADD45 expression.
\end{abstract}

Methods: A total of 24 locally advanced, non-metastatic oral cancer patients were included in the study. Tumor biopsies were taken prior to the start of neoadjuvant therapy for expression of EGFR, Her-2-Neu, and GADD45 by immunohistochemistry and for HPV by PCR. The response was evaluated using Response Evaluation Criteria in Solid Tumors (RECIST) criteria after three cycles of chemotherapy. Statistical analysis was performed using correlation and Kaplan-Meier analysis; the difference in survival was calculated with log rank test.

Results: A total of 21 male and 3 female with a mean age of 53.12 years were enrolled. Sixty-five percent of these received three cycles of chemotherapy. Five patients were positive for HPV 16 and none for HPV 18. Twenty-two of 24 patients showed GADD45 expression, 3 showed expression of Her-2-Neu while all 24 showed expression for EGFR1 protein. Two-year overall survival was 81\%; GADD45 expressions were found to significantly affect the overall and disease-free survival, while any of the other protein expression studied and HPV status was not significant.

Conclusion: The result of the present study shows significant downgrading of the oral cancers with neoadjuvant chemotherapy suggesting its utility in borderline operable cases. However, the response of chemotherapy does not appear to be related to the expression of EGFR, Her-2-Neu, and GADD45 protein or presence of HPV. Bone involvement, perineural invasion, and GADD45 expression significantly predict OS and DFS. All patients who did not express Gadd45 died before 2 years. Study with more subjects and longer follow-up should be carried out to elucidate this relation further.

Keywords: Oral cancer, Buccal mucosa, Tongue, Alveolus, Survival, EGFR, Her-2-neu, GADD45, Human papilloma virus

* Correspondence: manojpandey66@gmail.com

'Department of Surgical Oncology, Institute of Medical Sciences, Banaras Hindu University, Varanasi 221 005, India

Full list of author information is available at the end of the article 


\section{Background}

Head and neck cancer squamous cell carcinoma (HNSCC) is the sixth most common cancer with an annual incidence of approximately 4,00,000 worldwide. Two third of the global incidence is reported from developing countries, of which one third is from India. The survival rate of HNSCC is poor, and the disease has a poor prognosis. The treatment of early cancer is surgery; however, in later stages, the chemotherapy (CTh) and radiotherapy [1] are preferred. Several new chemotherapeutic agents including taxanes and platinums have been used as first-line treatment in head and neck cancer; however, the response rate with this doublet or triplet combination ranges from 40 to $60 \%$.

Human papilloma virus (HPV) has been reported to be a causative factor in a subset of HNSCC that usually has a favorable prognosis [2]. High-risk HPV (HPV 16, 18, and 33)-related HNSCC is associated with certain sexual behavior, such as oral sex and increasing numbers of sexual partners, and these tumors usually lack association with smoking and alcohol [3]. Several studies and meta-analysis have confirmed that HPV-related HNSCC behaves differently from HPV-negative SCC and is associated with better treatment response to chemotherapy and radiation $[4,5]$.

Growth arrest and DNA damage repair (GADD45) gene plays important and diverse roles in the regulation of cellcycle [6]. Gadd 45 protein interacts with several regulatory pathways [7]. GADD45 promoter hypermethylation is frequently detected in tumor cell lines, including $85 \%$ of non-Hodgkin's lymphoma, $50 \%$ of Hodgkin lymphoma, $73 \%$ of nasopharngeal, $50 \%$ of cervical, $29 \%$ of esophageal, and $40 \%$ of lung carcinomas [7]. The role of GADD45a as a potential therapeutic target has become a matter of interest due to the fact that it is upregulated on docetaxel treatment. Because of the various functions of GADD 45 in cell-cycle control and its dysregulation in cancer, chemotherapeutic and molecular agents targeting GADD45 proteins may serve as novel therapeutic interventions in cancer treatment. Ramachandran et al. [8] described GADD45a novel potential therapeutic target which has been highlighted by the fact that it is upregulated on docetaxel treatment and may contribute to docetaxel mediated cytotoxicity of prostate cancer. In other study, authors found an increase in the GADD45A and GADD45B in docetaxel- and estramustine-treated prostate cancer cells which suggest their affects in the induction of apoptosis [9].

EGFR family includes EGFR, Her-2-neu (c-erb-B-2), her-3 (c-erb-B-3), and her 4 (c-erb-B-4) [10]. EGFR and Her-2-neu is a transmembrane tyrosine kinase receptor with intrinsic tyrosine kinase activity [10]. Several studies have found correlation between EGFR overexpression and survival in oral SCC and HNSCC $[11,12]$. Their expression and association with therapeutic targets have been demonstrated.

The big challenge is to identify which treatment is best suited for the individual patient by studying tumor biology at a molecular level and identifying biomarkers for predicting the response to therapy. Aim of the study was to study the effect of neoadjuvant chemotherapy with docetaxel and carboplatin in locally advanced non-metaplastic oral squamous cell carcinomas and to correlate the tumor response and survival with HPV status, EGFR, Her-2-neu, and GADD45 expression.

\section{Methods \\ Patients}

A total of 24 patients attending the surgical oncology outpatient between December 2009 to August 2011 with histologically proven locally advanced, borderline operable oral squamous cell cancers (OSCC) were included in the study. Those who had a history of severe hypersensitivity reaction to docetaxel were excluded. The study was approved by the Institute Ethics Committee. Informed consent was taken from all the patients prior to recruitment and collection of specimen. Tissue was stored at $-80{ }^{\circ} \mathrm{C}$ till analysis.

Biopsy was taken to study the HPV positivity, EGFR, GADD45, and Her-2-neu expression. All patients underwent neoadjuvant chemotherapy (NACT) with docetaxel $80 \mathrm{mg} / \mathrm{m}^{2}$ and carboplatin $300 \mathrm{mg} / \mathrm{m}^{2}$ on day 1 as a three weekly regimen, and response of therapy was correlated to HPV positivity, EGFR, GADD45, and Her-2neu expression. Responses were evaluated by clinical examination and post therapy CT scan by Response Evaluation Criteria in Solid Tumors (RECIST) criteria (complete response, partial response, progressive disease, and stable disease).

\section{Expression analysis by PCR}

DNA isolation DNA isolation was carried out by phenol-chloroform-isoamyl alcohol method.

PCR Consensus primers were used to amplify the HPV16 and HPV18, i.e., MY09/11 and GP05/06. Primer sequence for MY09/11 was MY09-5'-CGTCCMARRGGAWACT GATC-3' and MY11-5'-GCMCAGGGWCTATAAYA ATGG-3' and product size was 450 bp for HPV 16, while primer sequence for GP05/06 was GP-05-5'-TTTGT TACTGTGGTAGATACYAC-3' and GP-06-5'-GAAAA ATAAACTGTAAATCATATTC-3' and product size was $140 \mathrm{bp}$ for HPV 18. PCR was conducted in Biometra Thermal Cycler. Reaction mixture contains micromole of oligonucleotide, $2 \times$ PCR buffer, 100 ng of DNA template, 
and nuclease-free water. Hot start PCR program for both primers are initial denaturation at $95{ }^{\circ} \mathrm{C}$ for $5 \mathrm{~min}$, denaturation at $94{ }^{\circ} \mathrm{C}$ for $45 \mathrm{~s}$, annealing at $47.5^{\circ} \mathrm{C}$ for $45 \mathrm{~s}$, extension at $72{ }^{\circ} \mathrm{C}$ for $45 \mathrm{~s}$ followed by 40 cycles, and final extension at $72{ }^{\circ} \mathrm{C}$ for $7 \mathrm{~min}$. Agarose gel electrophoresis was carried out to check the PCR amplification.

\section{Immunohistochemistry}

Immunohistochemistry was performed on formalin-fixed paraffin blocks which cut at a thickness of $2 \mu \mathrm{m}$. These sections were deparaffinized in xylene followed by hydration in a graded series of alcohols. Sections were left under running water for $15 \mathrm{~min}$. Endogenous peroxidase activity was blocked by incubation in $3 \%$ hydrogen peroxide for $30 \mathrm{~min}$ at room temperature. After rinsing in TBS buffer ( $\mathrm{pH} 7.4$ ) for $30 \mathrm{~min}$, the sections were incubated with primary antibody at $4{ }^{\circ} \mathrm{C}$ overnight. The following primary antibodies were used: EGFR (SantaCruz Biotechnology, Santa Cruz, CA), GADD45A (Abcam, Cambridge, MA), and Her-2-neu (Biogenex). Slides were then washed again in TBS. Secondary antibody was added, and slides were washed again after $30 \mathrm{~min}$. The labeled antigen-antibody complexes were visualized as brown pigments via a standard DAB (Zhongshan Jinqiao Co., Beijing, China) protocol. DAB was added and kept for $10 \mathrm{~min}$ until brown color developed. Slides were washed in running water, and counterstaining was done with hematoxylin. Slides were then blotted, dried, and mounted.

\section{Statistical analysis}

Correlations were performed by using Pearson's and Spearman's correlation coefficient with two-tailed significance. Survival was compared using Kaplan-Meier method, and the difference in survival was compared by using log rank test. $p<0.05$ was considered as statistically significant. Analyses were performed with SPSS software (version 13.0; SPSS Inc., Chicago, IL, USA).

\section{Results}

\section{Clinicopathological features}

Out of 24 patients enrolled, 21 (87.5\%) and 3 (12.5\%) were males and females respectively. Mean age of the study population was 53.12 years (range 25-72 years). Eighty-eight percent of the patients had the habit of tobacco and alcohol, and only $2 \%$ patient did not have the habit of tobacco consumption in any form. Most of the cases were of carcinoma of buccal mucosa (29\%), lower alveolus (25\%), and tongue (25\%). The most common symptoms among the patients were ulcer (96\%) and pain (71\%). Other symptoms include dyspahgia (17\%), loosening of teeth (17\%), bleeding (13\%), trismus (13\%), and dysarthia $(8 \%)$. The primary growth was of ulceroproliferative type in $50 \%$ patients and of infiltrative type in 50\% cases. Eighteen out of 24 patients had extension to the adjacent skin, muscle, or bone either alone or combination of more than one. Majority of the patients had T4 disease (19; 79\%) while 13 (54\%) had N2 disease (Table 1).

HPV status, GADD-45, EGFR, and Her-2-neu expression PCR for HPV was performed on the tumor samples in all the 24 patients. Out of 24 samples, 5 were found to be positive for HPV16 type whereas HPV18 was not found in any of the cases (Fig. 1). GADD45 expression was shown in $22(92 \%)$ out of 24 patients. All the patients had cytoplasmic expression of GADD45 (Fig. 2).

Table 1 Clinicopathological characteristics of oral squamous cell carcinoma

\begin{tabular}{|c|c|}
\hline Parameters & Frequency \\
\hline \multicolumn{2}{|l|}{ 1. Gender distribution } \\
\hline Male & $21(87.5 \%)$ \\
\hline Female & $3(12.5 \%)$ \\
\hline \multicolumn{2}{|l|}{ 2. Age distribution } \\
\hline Mean & 53.12 years \\
\hline \multicolumn{2}{|l|}{ 3. Precancerous lesion } \\
\hline No precancerous lesion & $22(92 \%)$ \\
\hline Leucoplakia & $2(8 \%)$ \\
\hline \multicolumn{2}{|c|}{ 4. Habit of tobacco chewing and alcohol addiction } \\
\hline Single habit present & $21(88 \%)$ \\
\hline Absent & $2(8 \%)$ \\
\hline Tobacco + alcohol & $1(4 \%)$ \\
\hline \multicolumn{2}{|l|}{ 5. Site of distribution } \\
\hline Buccal mucosa & $7(29 \%)$ \\
\hline Lower alveolus & $6(25 \%)$ \\
\hline Tongue & $6(25 \%)$ \\
\hline Retromolar trigone & $3(13 \%)$ \\
\hline Lower lip & $1(4 \%)$ \\
\hline GB sulcus & $1(4 \%)$ \\
\hline \multicolumn{2}{|l|}{ 6. TNM stage } \\
\hline $\mathrm{T} 2$ & $3(13 \%)$ \\
\hline T3 & $2(8 \%)$ \\
\hline T4a & $19(79 \%)$ \\
\hline NO & $3(13 \%)$ \\
\hline N1 & $8(33 \%)$ \\
\hline $\mathrm{N} 2 \mathrm{~b}$ & $11(46 \%)$ \\
\hline $\mathrm{N} 2 \mathrm{C}$ & $2(8 \%)$ \\
\hline MO & 0 \\
\hline \multicolumn{2}{|l|}{ 7. Stage grouping } \\
\hline III & $3(13 \%)$ \\
\hline IVA & 21 (87\%) \\
\hline
\end{tabular}




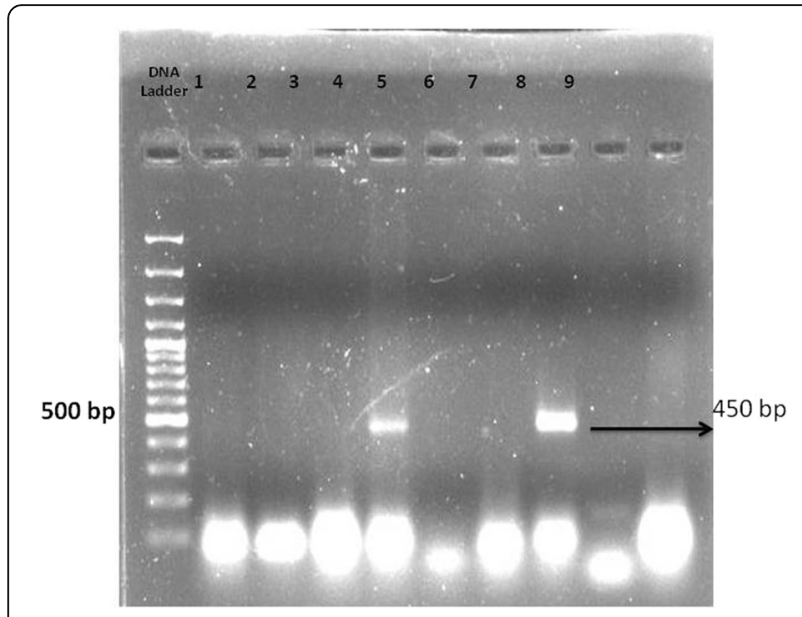

Fig. 1 Image showing the HPV16 status in oral squamous cell carcinoma

There was only one patient which had additional staining also. Grade I staining was present in $2(6 \%)$, grade II in 15 (63\%), and grade III in 5 (21\%) patients (Fig. 2). EGFR was expressed in all the cases (100\%). EGFR showed grade I staining in $6(25 \%)$, grade II in $8(33 \%)$, and grade III in 10 (42\%) patients (Fig. 3). Out of 24 samples, only $3(12.5 \%)$ samples expressed Her-2-neu. The expression was mild in all the 3 cases (Fig. 4).

Out of 24 patients, 2 patients received 2 cycles, 15 received 3,3 patients received 5 , and only 1 patient received 6 cycles of neoadjuvant chemotherapy with docetaxel $\left(80 \mathrm{mg} / \mathrm{m}^{2}\right)$ and carboplatin $\left(300 \mathrm{mg} / \mathrm{m}^{2}\right)$. The response to CTh was assessed according to RECIST criteria. One (4\%), 11 (46\%), 8 (33\%), and 4 (17\%) patients had complete, partial, stable, and progressive response on $\mathrm{CTh}$ respectively. The overall response rate was $50 \%$. The response of NACT on the size of tumor was compared before and after CTh. The mean length and breadth of the lesions before
CTh were 4.18 and $2.8 \mathrm{~cm}$ while post CTh, it was 3.22 and $2.6 \mathrm{~cm}$ respectively.

\section{Correlation between markers, $\mathrm{T}$ and $\mathrm{N}$ stage, performance status, and response}

Her-2-neu was expressed in tumors with high EGFR expression. The correlation coefficient $(r)$ was 0.4 , and $p$ value is 0.048 . There was no statistically significant correlation between CTh response and EGFR, Her-2-neu, and GADD45 expression, and HPV status (Table 2). Patients with HPV-positive tumors have a better performance status $(r=+0.39, p<0.05)$. Patients with better performance status have a better response to CTh $(r=+0.52, p<0.05)$. No significant correlation was observed between T, N, and composite stage and the markers under study (Table 2).

\section{Two-year survival}

The 2-year overall survival (OS) was $81 \%$. There were 2 females on follow-up, and both of them died within 1 year. In males, the 2-year overall survival was $89 \%(p=0.00)$. Two-year overall survival by GADD45 expression grade was significantly different. Of the 24 patients, only 2 did not express GADD45 and both of them died at 2 years. There was no statistical significant difference in 2-year overall survival with relation to HPV status, EGFR, and Her-2-neu expression (Table 3).

\section{Disease-free survival}

The overall 2-year disease-free survival (DFS) in the study was $66.7 \%$ (Figs. 5 and 6). Those cases which did not express GADD45 had a 0\% 2-year DFS while it was $100,58.3$, and $100 \%$ in grade 1,2 , and 3 staining respectively. The difference was statistically significant $(p=0.012)$; however, it was not consistent pattern. The 2-year DFS in HPV-positive patients was $100 \%$ and in HPV-negative patients, $56.2 \%(p=0.077)$; the HPV-positive patients had better DFS; however, it did not reach statistical significance

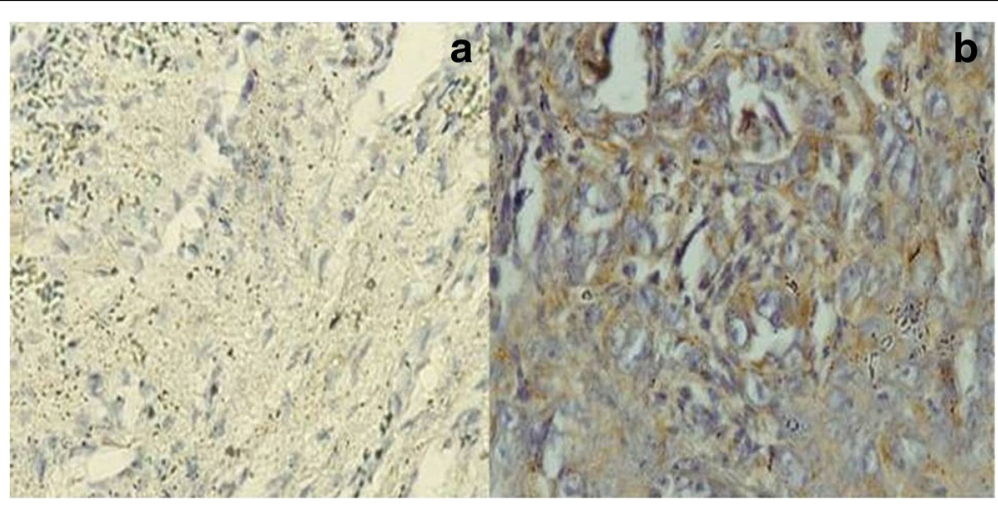

Fig. 2 Immunohistochemistry for GADD45: a Grade 1 positive cytoplasmic staining and $\mathbf{b}$ grade 3 positive nuclear and cytoplasmic staining in oral squamous cell carcinoma 


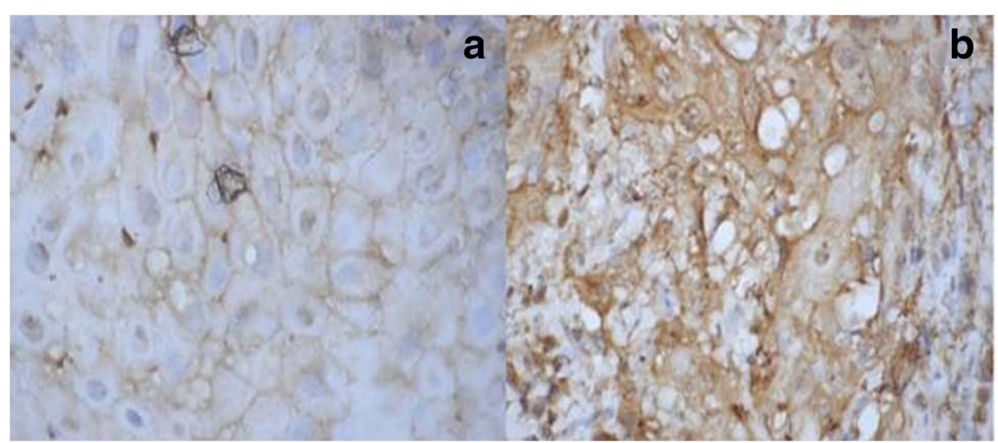

Fig. 3 Immunohistochemistry for EGFR: a weak positive staining and $\mathbf{b}$ strong positive staining in oral squamous cell carcinoma

(Fig. 7). EGFR and Her-2-neu did not correlate significantly with 2-year DFS.

\section{Discussion}

The treatment of squamous cell carcinoma of head and neck (HNSCC) has been the realm of surgeons and radiation oncologists. There has been a paradigm shift in the management of HNSCC over the last two decades, and now, chemotherapy (CTh) is an integral part of the management. Therefore, it is a big challenge to individualize the treatment. Thus, this study was done to identify predictors of response to CTh with docetaxelbased regimen in locally advanced oral squamous cell carcinoma and correlated the tumor response with HPV status, EGFR, Her-2-neu, and GADD45 expression. In our study, $46 \%$ of patients had partial response to CTh. The complete response rate (CRR) was $41.6 \%$, and overall response rate (ORR) was 50\%. Lip tumors responded best to CTh followed by GB sulcus tumors, $57 \%$ of buccal mucosa, $50 \%$ each of tongue and alveolus lesion responded to CTh. Colevas et al. reported a CRR of $61 \%$ and ORR of $100 \%$ using the TPFLS regimen in 23 patients with HNSCCC [13]. Their other study also reported a CRR of $63 \%$ and ORR of $93 \%$ in 30 patients with HNSCC [13] using the TPFl4 regime. While Posner et al. in 2001 got a CRR of $40 \%$ and ORR of $93 \%$ in 43 patients with HNSCC using the TPF regimen [14]. Watanabe et al. in 2004 [15] reported a CRR of 59\% and ORR of $88 \%$ in 34 patients with HNSCC using the TPF regimen with a lower done of docetaxel. In the phase III TAX323 trial which used induction CT with TPF regimen followed by RT, the CRR was $8.5 \%$ and ORR was $68 \%[16,17]$. Albers et al. [18] recently reported an overall response rate of $86 \%$ and 3-year survival of $65 \%$ using the docetaxel-based chemotherapy in combination in locally advanced cancer wherein 30/45 of his patients were treated with curative intent. Though role of neoadjuvant chemotherapy in head and neck cancers is debatable, however, recent evidence suggests some possible role. Inhestern et al. [19] reported a 97\% 2-year OS for responder compared to $76 \%$ in those who did not respond to TPF therapy. In all of the patients, the chemotherapy was followed by surgery and concurrent chemoradiation. However, all other studies have failed to show any improvement in the overall or disease-free survival, and some have even showed disease progression and operative complications in patients receiving neoadjuvant chemotherapy [20-23].



Fig. 4 Immunohistochemistry for Her-2-neu: a negative staining and b positive staining in oral squamous cell carcinoma 
Table 2 Expression status of EGFR, GADD-45, EGFR, and Her-2neu and response rate of chemotherapy on oral cancer patients

\begin{tabular}{|c|c|c|c|c|c|}
\hline & GADD45 & HPV status & EGFR status & Her-2-neu & Response \\
\hline \multicolumn{6}{|c|}{ GADD45 } \\
\hline$r$ & 1 & 0.292 & -0.047 & -0.076 & -0.263 \\
\hline$p$ & - & 0.187 & 0.834 & 0.735 & 0.236 \\
\hline$N$ & 22 & 22 & 22 & 22 & 22 \\
\hline \multicolumn{6}{|c|}{ HPV status } \\
\hline$r$ & 0.292 & 1 & -0.095 & -0.116 & 0.103 \\
\hline$p$ & 0.187 & - & 0.659 & 0.508 & 0.633 \\
\hline$N$ & 22 & 24 & 24 & 24 & 24 \\
\hline \multicolumn{6}{|c|}{ EGFR status } \\
\hline$r$ & -0.047 & -0.095 & 1 & 0.408 & 0.321 \\
\hline$p$ & 0.834 & 0.659 & - & 0.048 & 0.126 \\
\hline$N$ & 22 & 24 & 24 & 24 & 24 \\
\hline \multicolumn{6}{|c|}{ Her-2-neu } \\
\hline$r$ & -0.076 & 0.116 & 0.408 & 1 & 0.378 \\
\hline$p$ & 0.735 & 0.588 & 0.048 & - & 0.069 \\
\hline$N$ & 22 & 24 & 24 & 24 & 24 \\
\hline \multicolumn{6}{|c|}{ Response } \\
\hline r & -0.263 & 0.103 & 0.321 & 0.378 & 1 \\
\hline$p$ & 0.236 & 0.633 & 0.126 & 0.064 & - \\
\hline$N$ & 22 & 24 & 24 & 24 & 24 \\
\hline
\end{tabular}

$r$ correlation coefficient, $p$ value, $N$ no of positive patients

\section{Correlation of EGFR, Her-2-neu, and GADD45 expression and HPV status with response to NACT with docetaxel and survival}

In our study, all the cases expressed EGFR while Her-2neu was expressed in 3 (12.5\%) out of 24 patients. Her2-neu expression was associated with high EGFR expression (correlation coefficient $r=0.4 ; p=0.048$ ). Neither EGFR expression nor Her-2-neu expression was significantly associated with response to CTh with docetaxel $(r=0.321 ; p=0.126$ and $r=0.378 ; p=0.69$ for EGFR and Her-2-neu respectively) and with 2-year disease-free and overall survival. In an earlier study, EGFR was expressed in $79.4 \%$ of cases of recurrent HNSCC [24]. EGFR-positive tumors had a 3-year cause-specific survival of $27.2 \%$ after salvage surgery whereas EGFR-negative tumors had a 3 -year cause-specific survival of $64.3 \%(p<0.001)$ [24]. The EGFR expression alone had no significant impact on survival [24]. In another study by Shiraki et al., the overall EGFR expression was 39\% and in T3 and T4 lesions, it was $37 \%$. In the same study, co-expression of EGFR, p53, and cyclin D1 was associated with shortened survival [11]. Xia et al. observed that at the combine expression of EGFR, Her-2-neu and Her-3 is a stronger predictor of outcome in oral SCC than any individual family members of the EGFR family [12]. EGFR expression (87.5\%) was not found to be associated with proliferation, apoptosis, angiogenesis, and lymphangiogenesis in oral SCC [25]. Chen et al. looked at the EGFR and Her-2-neu expression in oral SCC by enzyme immunoassay method. In their study, EGFR was overexpressed in 58\% tumors and Her-2-neu in 41\%. EGFR overexpression was significantly associated with TNM stage, lymph node involvement and extra capsular spread, and poor survival. Her-2-neu was not found to be associated with any of the above parameters [26].

GADD45 was expressed in $91.6 \%$ cases in the study. There was no significant association established between GADD45 expression and response to CTh with docetaxel and carboplatin $(r=0.263 ; p=0.236)$. But a significant association was there between GADD45 expression and 2-year disease-free and 2-year overall survival. Those cases which did not express GADD45 had a poor 2-year overall survival of $0 \%$ compared to $81 \%$ when compared with positive cases $(p=0.005)$. There is no published report examining the role of GADD45 as a predictive marker of CT response or survival in LA HNSCC till date. In prostate cancer, upregulation of GADD45 levels has been associated with increased sensitivity to docetaxel in in vitro studies [8]. They have proposed that GADD45 was epigenetically repressed in prostate cancer and its upregulation may be a potential target for therapeutic strategies [8]. Another experimental study had concluded that tumors in GADD45 deficient mice show increased mutation frequency and increased susceptibility to ionizing radiation and to chemical carcinogens [27]. All our cases that expressed GADD45 did so before starting the CTh, and post therapy evaluation was not carried out in this study.

\section{HPV positivity and correlation with CTh response and survival}

In our study, PCR for HPV 16 and 18 types were performed and only 5 (20.83\%) was found to be HPV 16 type positive. Like our previous study, this study too failed to demonstrate any significant association between HPV status and response to NACT with docetaxel and carboplatin $(r=0.103 ; p=0.633)$ [5]. The 2-year overall survival in HPV-positive patient was 100\% and in HPV negative patients, $75 \%$, and the difference was not significant $(p=0.234)$. The 2-year DFS in HPV-positive patients was $100 \%$ and in HPV negative patients were $56.2 \%$, and the difference was almost approached statistically significant $(p=0.077)$.

The impact of HPV on cancer risk and overall survival in head and neck squamous cell carcinomas has been summarized in a meta-analysis, concluding that $21.95 \%$ of HNSCC patients are HPV positive and the prevalent genotype is HPV-16 (86.69\%). A better survival in HPVpositive patients has been reported compared to HPVnegative cases [27]. Prevalence of HPV is reported to be $41 \%$ in oropharengeal cancers [28]. Fakhry et al. looked 
Table 3 Association of the 2-year overall survival and disease-free survival with different clinicopathological variables and biomarkers

\begin{tabular}{|c|c|c|c|c|}
\hline & 2-year overall survival (OS) (\%) & $p$ value & 2-year disease-free survival (DSF) (\%) & $p$ value \\
\hline \multicolumn{5}{|l|}{ Gender } \\
\hline Male & 89.5 & $0.00^{*}$ & 73.7 & $0.00^{*}$ \\
\hline Female & 0 & & 0 & \\
\hline \multicolumn{5}{|l|}{ T stage } \\
\hline $\mathrm{T} 2$ & 100 & 0.541 & 33.3 & 0.18 \\
\hline T3 & 100 & & 50 & \\
\hline T4 & 75 & & 75 & \\
\hline \multicolumn{5}{|l|}{ N stage } \\
\hline NO & 100 & 0.738 & 100 & 0.422 \\
\hline N1 & 75 & & 50 & \\
\hline N2 & 81.8 & & 72.7 & \\
\hline \multicolumn{5}{|c|}{ Skin involvement } \\
\hline Present & 100 & 0.242 & 100 & 0.095 \\
\hline Absent & 75 & & 56.2 & \\
\hline \multicolumn{5}{|c|}{ Bone involvement } \\
\hline Present & 90 & 0.282 & 90 & $0.023^{*}$ \\
\hline Absent & 72.7 & & 45.5 & \\
\hline \multicolumn{5}{|l|}{ GADD45 } \\
\hline 0 & 0 & $0.005^{*}$ & 0 & $0.012^{*}$ \\
\hline 1 & 100 & & 100 & \\
\hline 2 & 83.3 & & 58.3 & \\
\hline 3 & 100 & & 100 & \\
\hline \multicolumn{5}{|l|}{ HPV status } \\
\hline Positive & 100 & 0.234 & 100 & $0.077^{* *}$ \\
\hline Negative & 75 & & 56.2 & \\
\hline \multicolumn{5}{|c|}{ EGFR grading } \\
\hline 1 & 83.3 & 0.566 & 83.3 & 0.518 \\
\hline 2 & 60 & & 40 & \\
\hline 3 & 90 & & 70 & \\
\hline \multicolumn{5}{|l|}{ Her-2-neu } \\
\hline Positive & 100 & 0.392 & 66.7 & 0.933 \\
\hline Negative & 77.8 & & 66.7 & \\
\hline \multicolumn{5}{|c|}{ Pathological lymph node involvement } \\
\hline Present & 81.8 & 0.899 & 63.7 & 0.47 \\
\hline Absent & 80 & & 70 & \\
\hline \multicolumn{5}{|c|}{ Vascular invasion } \\
\hline Present & 71.4 & 0.273 & 66.7 & 0.86 \\
\hline Absent & 88.9 & & 71.4 & \\
\hline \multicolumn{5}{|c|}{ Perineural invasion } \\
\hline Present & 57.1 & $0.05^{*}$ & 57.1 & 0.36 \\
\hline Absent & 100 & & 77.8 & \\
\hline \multicolumn{5}{|c|}{ Lymphatic invasion } \\
\hline Present & 71.4 & 0.273 & 66.7 & 0.86 \\
\hline Absent & 88.9 & & 71.4 & \\
\hline
\end{tabular}






Fig. 5 Disease-free survival

at the impact of HPV positivity on survival in stage 3 and 4 oropharengeal cancers and reported that the HPV-positive patients had higher response rate after induction CTh $(p=0.01)$ than HPV-negative patients and after chemoradiation treatment $(p=0.007)$ [28].

Another study also reported that presence of HPV was significantly correlated with a better survival in patients with oral squamous cell carcinoma [29]. Most of the studies have reported a role of HPV as a predictor to response to treatment though our study failed to do so. That may be due to small sample size. Studies with larger sample size may clarify their association better.

\section{Relation of survival with other parameters}

In our study, 2-year OS and DFS were 81 and $66.7 \%$ respectively. Colevas et al. had got an $83 \% 2$ year OS by using TPF regimen [30]. Some other authors also observed a $60 \% 2$-year OS by using TPF regimen [31]. Others have also found a 2-year OS as $79,60,41$, and $93 \%[15,31-33]$. Another group demonstrated a 3-year OS with the TPF regimen and got only 29.6 [34]. These results showed that the response rates have been variable. It appears that the genetic and molecular characteristics of the tumor do play a role; however, so far, no such

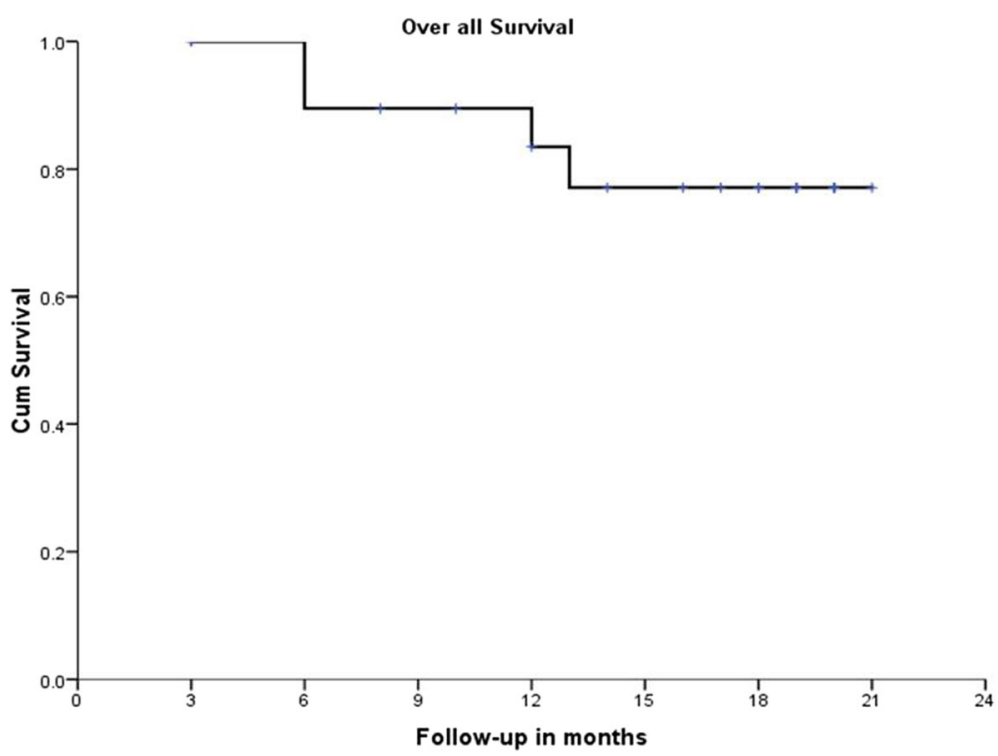

Fig. 6 Overall survival 


\section{Survival by presence of HPV}

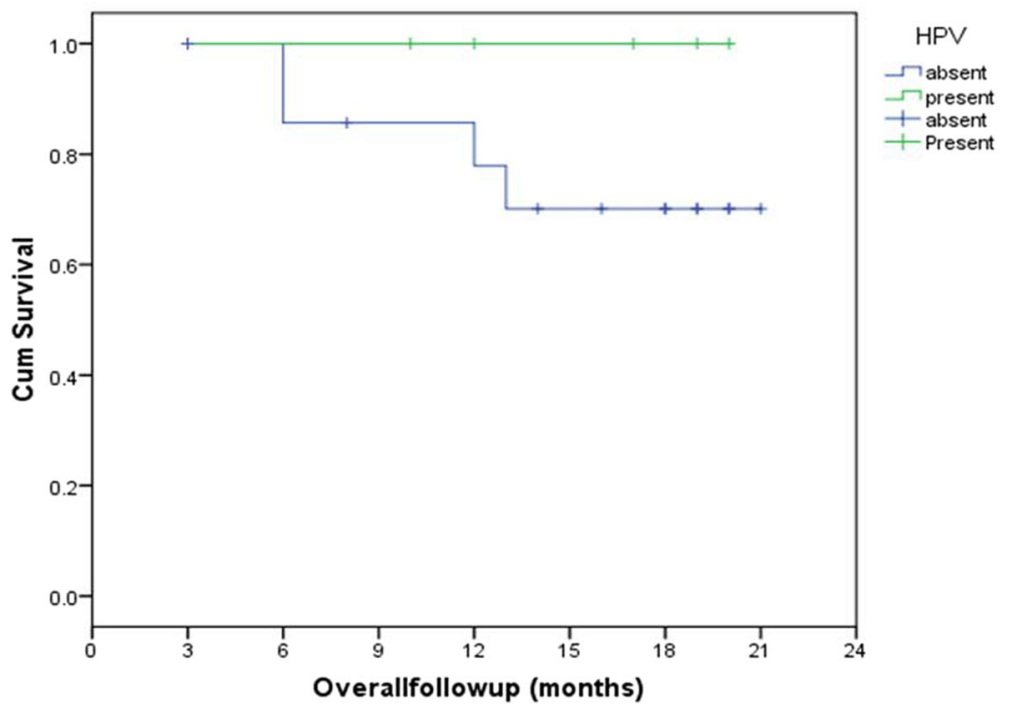

Fig. 7 Survival by presence of HPV

markers for prediction of the tumor response have been identified.

\section{Conclusions}

Our findings suggests that HPV status, EGFR, and GADD45 be assessed in OSCC as together they may help in predicting the survival of the patients; though GADD45 expression was found to predict survival and DFS, however, it did not predict the response to chemotherapy with docetaxel.

\section{Acknowledgements \\ None}

\section{Funding}

None

\section{Availability of data and materials}

The data is available with the authors.

\section{Authors' contributions}

MP contributed to the concept and design, data analysis interpretation, and editing of the final manuscript. KKK contributed to the concept and design and data collection analysis and interpretation. RD contributed to the molecular analysis, interpretation of data, and preparation of the draft manuscript. MK contributed to the pathological and $\mathrm{IHC}$ analysis and interpretation and preparation of the manuscript. All authors read and approved the final manuscript.

\section{Ethics approval and consent to participate}

The study was approved by the Institute Ethics Committee, and informed consent was obtained from each participant.

\section{Consent for publication}

The written informed consent was obtained from each patient enrolled in this study; the study was approved by the Institute Ethics Committee.

\section{Competing interests}

The authors declare that there are no competing interests.

\section{Publisher's Note}

Springer Nature remains neutral with regard to jurisdictional claims in published maps and institutional affiliations.

\section{Author details}

${ }^{1}$ Department of Surgical Oncology, Institute of Medical Sciences, Banaras Hindu University, Varanasi 221 005, India. ${ }^{2}$ Department of Surgery, Institute of Medical Sciences, Banaras Hindu University, Varanasi 221 005, India. ${ }^{3}$ Department of Pathology, Institute of Medical Sciences, Banaras Hindu University, Varanasi 221 005, India.

Received: 8 September 2017 Accepted: 5 January 2018 Published online: 31 January 2018

\section{References}

1. Jacobs C, Goffinet DR, Goffinet L, Kohler M, Fee WE. Chemotherapy as a substitute for surgery in the treatment advanced resectable head and neck cancer. A report from the Northern California Oncology Group. Cancer. 1987;60(6):1178-83.

2. Pignon JP, Bourhis J, Domenge C, Designé L. Chemotherapy added to locoregional treatment for head and neck squamous-cell carcinoma: three meta-analyses of updated individual data. MACH-NC collaborative group. Meta-analysis of chemotherapy on head and neck cancer. Lancet 2000; 355(9208):949-955.

3. Gillison ML, D'Souza G, Westra W, Sugar E, Xiao W, Begum S, Viscidi R. Distinct risk factor profiles for human papillomavirus type 16-positive and human papillomavirus type 16-negative head and neck cancers. J Natl Cancer Inst. 2008;100(6):407-20.

4. Chung $\mathrm{CH}$, Gillison ML. Human papillomavirus in head and neck cancer: its role in pathogenesis and clinical implications. Clin Cancer Res. 2009;15(22): 6758-62.

5. Kumar A, Kumar M, Dixit R, Jaiswal R, Srivastava V, Pandey M. Presence of human papilloma virus and EGFR expression does not predict response to Neoadjuvant chemotherapy in oral cancer. World J Surg Med Radiat Oncol. 2012;1:103-10.

6. Butz K, Whitaker N, Denk C, Ullmann A, Geisen C, Hoppe-Seyler F. Induction of the p53-target gene GADD45 in HPV-positive cancer cells. Oncogene. 1999:18(14):2381-6

7. Cretu A, Sha X, Tront J, Hoffman B, Liebermann DA. Stress sensor Gadd45 genes as therapeutic targets in cancer. Cancer Ther. 2009:7(A):268-76.

8. Ramachandran K, Gopisetty G, Gordian E, Navarro L, Hader C, Reis IM, Schulz WA, Singal R. Methylation-mediated repression of GADD45alpha in prostate cancer and its role as a potential therapeutic target. Cancer Res. 2009;69(4):1527-35. 
9. Li Y, Hong X, Hussain M, Sarkar SH, Li R, Sarkar FH. Gene expression profiling revealed novel molecular targets of docetaxel and estramustine combination treatment in prostate cancer cells. Mol Cancer Ther. 2005;4(3):389-98.

10. Burgess AW. EGFR family: structure physiology signalling and therapeutic targets. Growth Factors. 2008;26(5):263-74

11. Shiraki M, Odajima T, Ikeda T, Sasaki A, Satoh M, Yamaguchi A, Noguchi M, Nagai I, Hiratsuka H. Combined expression of p53, cyclin D1 and epidermal growth factor receptor improves estimation of prognosis in curatively resected oral cancer. Mod Pathol. 2005;18(11):1482-9.

12. Xia W, Lau YK, Zhang HZ, Xiao FY, Johnston DA, Liu AR, Li L, Katz RL, Hung MC. Combination of EGFR, HER-2/neu, and HER-3 is a stronger predictor for the outcome of oral squamous cell carcinoma than any individual family members. Clin Cancer Res. 1999;5(12):4164-74.

13. Colevas AD, Norris CM, Tishler RB, Fried MP, Gomolin HI, Amrein P, Nixon A, Lamb C, Costello R, Barton J, Read R, Adak S, Posner MR. Phase II trial of docetaxel, cisplatin, fluorouracil, and leucovorin as induction for squamous cell carcinoma of the head and neck. J Clin Oncol. 1999;17(11):3503-11.

14. Posner MR, Glisson B, Frenette G, Al-Sarraf M, Colevas AD, Norris CM, Seroskie JD, Shin DM, Olivares R, Garay CA. Multicenter phase I-II trial of docetaxel, cisplatin, and fluorouracil induction chemotherapy for patients with locally advanced squamous cell cancer of the head and neck. J Clin Oncol. 2001;19(4):1096-104.

15. Watanabe A, Taniguchi M, Sasaki S. Induction chemotherapy with docetaxel, cisplatin, fluorouracil and I-leucovorin for locally advanced head and neck cancers: a modified regimen for Japanese patients. Anti-Cancer Drugs. 2003; 14(10):801-7.

16. Remenar E, Van Herpen C, Germa Lluch J, et al. A randomized phase III multicenter trial of neoadjuvant docetaxel plus cisplatin and 5-fluorouracil (TPF) versus neoadjuvant PF in patients with locally advanced unresectable squamous cell carcinoma of the head and neck (SCCHN). Final analysis of EORTC 24971. J Clin Oncol. 2006;24(Suppl 18):5516.

17. Vermorken JB, Remenar E, van Herpen C, Gorlia T, Mesia R, Degardin M, Stewart JS, Jelic S, Betka J, Preiss JH, van den Weyngaert D, Awada A, Cupissol D, Kienzer HR, Rey A, Desaunois I, Bernier J, Lefebvre JL; EORTC 24971/TAX 323 study group. Cisplatin, fluorouracil, and docetaxel in unresectable head and neck cancer. N Engl J Med 2007;357(17):1695-1704.

18. Albers AE, Grabow R, Qian X, Jumah MD, Hofmann VM, Krannich A, Pecher G. Efficacy and toxicity of docetaxel combination chemotherapy for advanced squamous cell cancer of the head and neck. Mol Clin Oncol. 2017;7(1):151-7. https://doi.org/10.3892/mco.2017.1281. Epub 2017 Jun 1

19. Inhestern J, Schmalenberg H, Dietz A, Rotter N, Maschmeyer G, Jungehülsing M, Grosse-Thie C, Kuhnt T, Görner M, Sudhoff H, Wittekindt C, Guntinas-Lichius O. A two-arm multicenter phase II trial of one cycle chemoselection split-dose docetaxel, cisplatin and 5-fluorouracil (TPF) induction chemotherapy before two cycles of split TPF followed by curative surgery combined with postoperative radiotherapy in patients with locally advanced oral and oropharyngeal squamous cell cancer (TISOC-1). Ann Oncol. 2017;28(8):1917-22. https://doi.org/10.1093/annonc/mdx202.

20. Hirakawa H, Hanai N, Suzuki H, Nishikawa D, Matayoshi S, Hasegawa Y, Suzuki M. Prognostic importance of pathological response to neoadjuvant chemotherapy followed by definitive surgery in advanced oral squamous cell carcinoma. Jpn J Clin Oncol. 2017;47(11):1038-46. https://doi.org/10. 1093/jjco/hyx097.

21. Kumar T, Kothari K, Patel MH, Ravi K, Yadav V. Surgical outcomes post neoadjuvant chemotherapy in stage IV cancers of oral cavity. Gulf J Oncolog. 2017;1(23):57-62.

22. Patil VM, Muttath G, Babu S, Kumar ST, Jones J, Sen S, Chakraborty S. Does the use of induction chemotherapy in oral cavity cancer compromise subsequent loco-regional treatment delivery: results from a matched pair analysis. Indian J Cancer. 2015;52(4):632-6. https://doi.org/10.4103/0019-509X.178442.

23. Sadighi S, Keyhani A, Harirchi I, Garajei A, Aghili M, Kazemian A, Motiee Langroudi M, Zendehdel K, Nikparto N. Neoadjuvant chemotherapy for locally advanced squamous carcinoma of oral cavity: a pilot study. Acta Med Iran. 2015;53(6):380-6.

24. Agra IM, Carvalho AL, Pinto CA, Martins EP, Filho JG, Soares FA, Kowalski LP. Biological markers and prognosis in recurrent oral cancer after salvage surgery. Arch Otolaryngol Head Neck Surg. 2008;134(7):743-9.

25. Sarkis SA, Abdullah BH, Abdul Majeed BA, Talabani NG. Immunohistochemical expression of epidermal growth factor receptor (EGFR) in oral squamous cell carcinoma in relation to proliferation, apoptosis, angiogenesis and lymphangiogenesis. Head Neck Oncol. 2010;2:13.

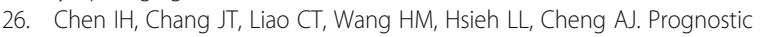
significance of EGFR and Her-2 in oral cavity cancer in betel quid prevalent area cancer prognosis. Br J Cancer. 2003;89(4):681-6.

27. Dayyani F, Etzel CJ, Liu M, Ho CH, Lippman SM, Tsao AS. Meta-analysis of the impact of human papillomavirus (HPV) on cancer risk and overall survival in head and neck squamous cell carcinomas (HNSCC). Head Neck Oncol. 2010:2:15.

28. Fakhry C, Westra WH, Li S, Cmelak A, Ridge JA, Pinto H, Forastiere A, Gillison ML. Improved survival of patients with human papillomavirus-positive head and neck squamous cell carcinoma in a prospective clinical trial. J Natl Cancer Inst. 2008;100(4):261-9.

29. Zhao D, Xu QG, Chen XM, Fan MW. Human papillomavirus as an independent predictor in oral squamous cell cancer. Int J Oral Sci. 2009;1(3):119-25.

30. Colevas AD, Busse PM, Norris CM, Fried M, Tishler RB, Poulin M, Fabian RL, Fitzgerald TJ, Dreyfuss A, Peters ES, Adak S, Costello R, Barton JJ, Posner MR. Induction chemotherapy with docetaxel, cisplatin, fluorouracil, and leucovorin for squamous cell carcinoma of the head and neck: a phase I/II trial. J Clin Oncol. 1998;16(4):1331-9.

31. Janinis J, Papadakou M, Panagos G, Panousaki A, Georgoulias V, Hatzidaki D, Lefantzis D, Dokianakis G. Sequential chemoradiotherapy with docetaxel, cisplatin, and 5-fluorouracil in patients with locally advanced head and neck cancer. Am J Clin Oncol. 2001;24(3):227-31.

32. Schrijvers D, Van Herpen C, Kerger J, Joosens E, Van Laer C, Awada A, Van den Weyngaert D, Nguyen H, Le Bouder C, Castelijns JA, Kaanders J, De Mulder P, Vermorken JB. Docetaxel, cisplatin and 5-fluorouracil in patients with locally advanced unresectable head and neck cancer: a phase I-II feasibility study. Ann Oncol. 2004;15(4):638-45.

33. Tsukuda M, Mikami Y, Tanigaki Y, Katori H, Horiuchi C, Ikeda Y, Taguchi T, Ono M, Yoshida T, Sakuma Y, Aikoh K. Phase I trial of combined chemotherapy with docetaxel, cisplatin, and 5-fluorouracil for patients with locally advanced squamous cell carcinoma of the head and neck. Int J Clin Oncol. 2004;9(3):161-6.

34. Umeda M, Komatsubara H, Ojima Y, Minamikawa T, Shigeta T, Shibuya Y, Yokoo S, Komori T. Lack of survival advantage in patients with advanced, resectable squamous cell carcinoma of the oral cavity receiving induction chemotherapy with cisplatin (CDDP), docetaxel (TXT) and 5-fluorouracil (5FU). Kobe J Med Sci. 2004;50(5-6):189-96.

\section{Submit your next manuscript to BioMed Central and we will help you at every step:}

- We accept pre-submission inquiries

- Our selector tool helps you to find the most relevant journal

- We provide round the clock customer support

- Convenient online submission

- Thorough peer review

- Inclusion in PubMed and all major indexing services

- Maximum visibility for your research

Submit your manuscript at www.biomedcentral.com/submit
C Biomed Central 